\title{
Spontaneous Rupture from a Liver Metastasis in a Case of Choriocarcinoma
}

\author{
GULL MOHD. BHAT, IRFAN HAKIM
}

\begin{abstract}
Spontaneous rupture of a secondary liver deposit is a rare occurrence. A young female patient of choriocarcinoma presented with liver secondaries, haemorrhage in peritoneum and rapidly developing shock. Following supportive treatment and chemotherapy she improved. To the best of our knowledge rupture of a liver metastasis from choriocarcinoma has not been reported.

\section{INTRODUCTION}

Spontaneous rupture from hepato cellular carcinoma is known ${ }^{1}$ but rupture from metastatic disease in liver occurs ${ }^{2-3}$ rarely. Although haemorrhagic manifestations of choriocarcinoma are common but necrotic liver secondaries with hemoperitoneum in choriocarcinoma are very rare..
\end{abstract}

CASE: A 27 years (G3, P1, A1) female presented in December 2004 with 5 months history of amenorrhea and easy exhaustion. Clinical examination revealed pallor, ascitis and a 12x 10 $\mathrm{cm}$ well circumscribed mass filling the lower abdomen. Ultrasonography scan showed evidence of molar pregnancy. On dilatation and curettage, products of conceptus were delivered but because of excessive bleeding, she underwent total abdominal hysterectomy (TAH) and inadvertently bilateral salpingooopherectomy (BSO). About 3-4 litres of ascitic fluid was drained. Histopathology revealed features of choriocarcinoma invading myometrium and at places, infiltration to serosal

Department of Medical Oncology, Sher-i-Kashmir Institute of Medical Sciences Soura, Sri Nagar (J \& K)

Correspondence to: GULL MOHD BHAT

Email: drgull18125@yahoo.com surface. Ovaries were normal. She was managed with cyclic chemotherapy as a low risk choriocarcinoma till March, 2005. Pre-operative $\beta-$ HCG levels were $700 \mathrm{i} . \mathrm{u} / \mathrm{ml}$. Serial beta HCG levels had normalized following which she received 2 more cycles. She was on regular follow up in outpatient department. In June 2007, she complained of right upper abdominal pain and distension of abdomen of sudden onset and presented to casualty in a state of shock.Her clinical evaluation revealed severe pallor, jaundice, nodular hepatomegaly with a palpable rub and free fluid in peritoneal cavity. She was managed conservatively with blood transfusions and plasma expanders. Repeat $\beta-$ HCG levels were raised. CECT abdomen showed multiple hypodense necrotic lesions in liver with subcapsular collection, nodular secondaries in the lung and free fluid in abdomen (Fig.1). Paracentesis revealed evidence of grossly bloody fluid. Patient received EMA-CO protocol which was later changed to BEP (bleomycim,

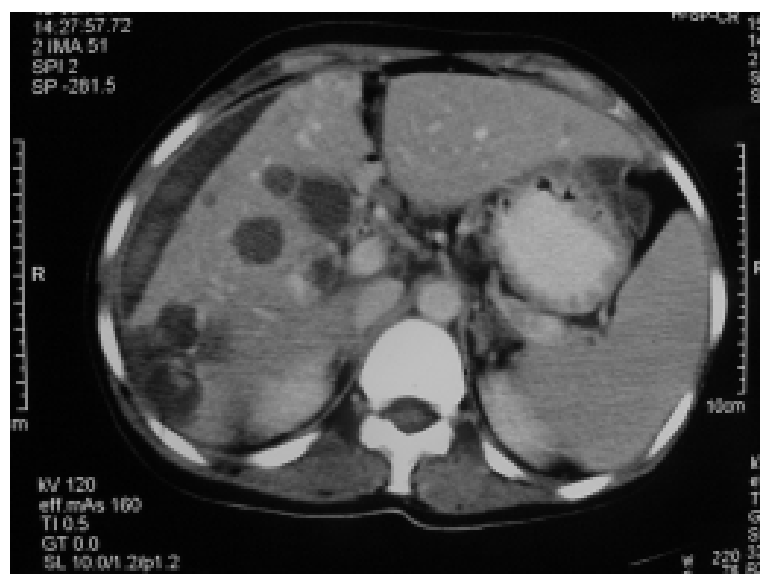

Fig.1: CECT liver showing cystic metastasis, subcapsular collection, ruptured secondary and free fluid in abdomen 
etoposide and cisplatin) chemotherapy. Abdominal girth decreased and liver secondaries regressed with reduction in $\beta-$ HCG values after 3 cycles of chemotherapy.

\section{DISCUSSION:}

Bleeding into peritoneum, uterine and vagina can be at times torrential and life threatening in choriocarcinoma. Massive transfusion, arterial embolization, lapratomy and even hysterectomy may be required to control the bleeding ${ }^{4}$ However, a patient relapsing with liver metastasis, subcapsular collection and hemoperitoneum/ hemorrhagic ascites, likely related to secondary rupture is not reported.

Rupture of liver metastasis has been anecdotally reported in various tumours e.g. gastric ${ }^{5}$, lung, ${ }^{6}$ esophagus cancers ${ }^{7}$, carcinoma of unknown primary, ${ }^{8}$ leiomyosarcoma, ${ }^{9}$ melanoma, ${ }^{10}$ renal cancer. ${ }^{11}$ Apart from metastasis, rupture from hepatocellular carcinoma and primary hepatic hemangioendothelioma ${ }^{12}$ can also occur. Choriocarcinoma, a gestational trophoblastic tumour can occur in young females and intra tumoural bleed is known in patients having lung or brain matastasis. However, we encountered a case of choriocarcinoma who presented with acute abdomen due to hemoperitoneum and bleeding from liver deposit. This case is being reported on account of its rarity. Treatment is liver resection, angioembolization and conservative with intent to control of bleeding. Rupture of liver metastasis should be considered in case a patient with liver metastasis presents with sudden pain, tender hepatomegaly, hepatic rub with rapidly developing free fluid in abdomen and/or shock.

\section{REFERENCES:}

1. Yamagata $M$, Maeda T, Ikeda $Y$ et al. Surgical results of spontaneously ruptured hepatocellular carcinoma. Hepatogastroenterology. 1995;42(5):461-4.

2. Cooperman AM, Weiland LH, Welch JS. Massive bleeding from a ruptured metastatic hepatic melanoma treated by hepatic lobectomy. Case report and review of the literature. Mayo Clin Proc. 1976;51(3):167-70.

3. Abrão A, Inácio de Paula $C$, da Silva Neto JB, Abrão Possik R, Capellano RS, Luizi A. [Acute spontaneous hemoperitoneum caused by rupture of a hepatic metastasis. Report of 5 cases]. AMB Rev Assoc Med Bras. 1974;20(12):431-4.

4. Michael J, Seckl, Fernando P et al. Gestational Trophoblastic Tumours. In Oxford Text book of Oncology, $2^{\text {nd }}$ Edition, 2001. Publ : Wolters Kluwer.

5. Yoshida H, Mamada Y, Taniai N. Ruptured metastatic liver tumour from an alpha-fetoprotein-producing gastric cancer. J Nippon Med Sch. 2005;72(4):236-41.

6. Kadowaki $T$, Hamada $H$, Yokoyama $A$ et al. Hemoperitoneum secondary to spontaneous rupture of hepatic metastasis from lung cancer. Intern Med. 2005;44(4):290-3.

7. Hosoda A, Tanaka K, Sasaki $S$ et al. An autopsy case of spontaneous rupture of the liver metastasis from esophageal cancer treated with transcatheter arterial embolization. Nippon Shokakibyo Gakkai Zasshi. 2002; 99(6):593-9.

8. Tung CF, Chang CS, Chow WK et al. Hemoperitoneum secondary to spontaneous rupture of metastatic epidermoid carcinoma of liver: case report and review of the literature. Hepatogastroenterology. 2002;49(47):1415-7.

9. Takayama T, Kato H, Tachimori $Y$ et al. Treatment of rupture of a liver metastasis from esophageal leiomyosarcoma. Jpn J Clin Oncol.1996;26(4):248-51.

10. Dousei T, Miyata M, Yamaguchi T et al. Rupture of liver metastasis of malignant melanoma-a case of hepatic resection. Jpn J Surg. 1991;21(4):480-4.

11. Wong KT, Khir AS, Noori $S$, et al. Fatal haemoperitoneum due to rupture of hepatic metastasis from renal cell carcinoma. Aust $N Z J$ Surg. 1994;64(2):128-9.

12. Lau WY, Dewar GA, Li AK. Spontaneous rupture of hepatic epithelioid haemangio-endothelioma. Aust NZ J Surg. 1989;59(12):972-4. 